\title{
The Pythagorean Symbolism in Plato's Philebus
}

\author{
By Kenneth R. Moore*
}

The Philebus contains what may be called a Pythagorean semiotics. That is, the dialogue has a number of embedded references and allusions to central aspects and ideas of Pythagoreanism. These act as signposts to the informed reader/auditor which illuminate certain topics of discussion in the dialogue and furnish a rich subtext which, when properly decoded, imparts a greater degree of sophistication and meaning to the text as a whole. One level of this may be observed in the Pythagorean allusions by themselves, of which there are many. A deeper level of Pythagorean semiotics arguably occurs in the very fabric of the dialogue itself. It has been argued that the Platonic dialogues have been deliberately structured according to a Pythagorean division of the musical canon, with certain themes corresponding to the consonance or dissonance of a given "note" on the scale. This, along with the relevant symbolism present, will be examined in greater detail.

The aim of Plato's Philebus is to determine the Good. It is replete with Pythagorean symbolism occurring at multiple levels. Kennedy has asserted that Plato used stichometric (word-counting) techniques to structure his dialogues corresponding to a Pythagorean, 12-note system as well as an Orphic, 7-note scale. Certain "notes" in the dialogue are therefore "more consonant" or "more dissonant", revealing a subtext of authorial intent. ${ }^{1}$ Kennedy has provided me with a schema of the Philebus according to this theory. I shall examine major instances of Pythagorean symbolism at the textual level here and attempt to address several key "notes" within Philebus in order to test Kennedy's model.

The dialogue is somewhat unusual inasmuch as it is considered a late production of Plato's, grouped chronologically with the Statesman and Laws, yet having Socrates as its protagonist. ${ }^{2}$ Its methodology is "classification" or "division" founded on principles, derived from Pythagorean sources, of the Limited and the Unlimited. ${ }^{3}$ Socrates says:

\footnotetext{
* Senior Lecturer in the History of Ideas, Teesside University, Middlesbrough, UK.

1. J. B. Kennedy, The Musical Structure of Plato's Dialogues (London: Acumen, 2011); J. B. Kennedy, "Plato's Forms, Pythagorean Mathematics, and Stichometry," Apeiron: a Journal for Ancient Philosophy and Science 43, no. 1 (2010): 1-32; Theon of Smyrna, Mathematics Useful for Understanding Plato, trans. R. Lawlor and D. Lawlor (San Diego, CA: Wizard's Bookshelf, 1979).

2. John M. Cooper and D. S. Hutchinson (Eds.), Plato: Complete Works (Indianapolis, IN: Hacket, 1997), 398.

3. Plato, Statesman, Philebus, Ion, trans. Harold N. Fowler (London: Heinemann, 1975), 200. See Plato's Letter XIII, 360b; see too Greg Lynch, "Limit and Unlimitedness in the Philebus: an argument for the Gadamerian reading," Apeiron 46, no.1 (2013): 48-62
} 
The people of old, superior to us and living in closer proximity to the gods, have bequeathed us this tale, that whatever is said to exist consists of One and Many, having in its nature Limit and the Unlimited (16c). ${ }^{4}$

This is the first notable reference to the Pythagoreans ("the people of old") and their theory of division. It sets the tone for the remainder of the dialogue and imposes a structured argument on the discussion of pleasure, initiated by Philebus' assertion that it is the Good. According to Socrates, all phenomena characterised by grades of intensity, e.g. pleasure and pain, belong to the Unlimited. Number, Measure and Knowledge fall within the Limited and are superior. ${ }^{5}$

This division in the Philebus recalls the Pythagorean Table of Opposites, which is organised with these very categories as its headers. The Table may be found in Aristotle's Metaphysics, reviewing earlier theories. There he (or his editor) has set down the Table which has found its way into the philosophy of Plato and others. ${ }^{6}$ This paradigm is particularly reflected in later dialogues such as the Laws. $^{7}$ It contains ten pairs of universal principles, beginning with the Limited/Unlimited, arranged as opposites (e.g., odd/even, male/female etc.) The polar relationship between "female" and "male", as with the rest of the attributes listed in the columns, is not coincidental. ${ }^{8}$ Ancient numerology posited odd numbers as naturally masculine and even numbers as feminine. Plutarch (c.46-c.126 c.e.) provides further insights into this in his On the Letter at Delphi. ${ }^{9}$ The sexual aspect of mixing the Limited with the Unlimited is also present in the Philebus.

Pythagorean division in the Philebus appears early in the dialogue when Socrates and Protarchus are deciding definitions and rules for the discussion (23c-d) about the "Limited (peiras) and the Unlimited (apeirōn)...while treating the third that results from the mixture of these two as our third kind." Socrates elaborates saying "whatever seems to us to become "more and less", or is subject to "strong and mild" or "too much" and all of that type" are part of the Unlimited (25a). Pleasure and pain admit "more and less" and belong here (41e ff.). The Limited, by contrast, not admitting "more and less", is their opposite. This includes anything that is a definite number or measure in

4. See Constance Chu Meinwald, "One/Many Problems," Phronesis 41 (1996): 95-103.

5. Plato. Statesman, Philebus, Ion, trans. Harold N. Fowler (London: Heinemann, 1975), 200; See Iamblichus, De vita Pyth. 6.30.

6. Metaphysics A.V.986a22 ff.; Walter Burkert, Lore and Science in Ancient Pythagoreanism trans. by Edwin L. Minar Jr. (Cambridge, MS: Harvard University Press, 1972), 51 ff. maintains it was authentic and influenced Plato; see too Constance Chu Meinwald, "Plato's Pythagoreanism," Ancient Philosophy 22 (2002): 87 -101.

7. Aristotle described Plato as "in most respects a follower of the Pythagoreans" (Met. A.V.987a30); and, see Peter Kingsley, Ancient Philosophy, Mystery, and Magic: Empedocles and the Pythagorean Tradition (Oxford: Clarendon Press, 1995) for an overview of the evidence.

8. See Walter Burkert, Lore and Science in Ancient Pythagoreanism, trans. Edwin L. Minar Jr. (Cambridge, MS: Harvard University Press, 1972), 125, 133 and 369 ff., and below.

9. 8.388a-e. Epsilon = 5. 
relation to such a number (25a-b). Socrates adds a third class to these, which "puts an end to the differences between opposites and makes them commensurable and harmonious by introduction of Number" (25d-e). The mixture of elements from the Limited and Unlimited, in appropriate combination, produces a harmonious mathematical concord and "creates a limit and establishes the whole art of music in all its perfection" (26a). ${ }^{10}$ Their appropriate admixture results in "moderation and due proportion", i.e. harmony. The connection with music here is significant and prefigures a dominant theme of the dialogue.

Socrates associates this process of proportionally applying Limit to the Unlimited with the actions of an unnamed divinity aiming at the betterment of humankind. He says "the goddess herself", observing that excess allowed no restraint upon pleasures, "imposed law and order as a limit upon them" (26b-c). This goddess may be Mousike, not "music" as we think of it, but the essence of Number and Measure which underscores all music. ${ }^{11}$ She stands in direct opposition to unrestrained Pleasure and makes it conform to the rules of order that she imposes. Here we have a clear case of Pythagorean number theory, detailed in metaphorical language, as an integral part of Socrates' argument. And there are other, more overt applications of this number theory elsewhere.

In note 6, quarter-note 3 (lines 43a ff.), Socrates introduces the Heracleitan doctrine of flux, only to dismiss it as extraneous. Note 6 on the Pythagorean scale is one of the more consonant notes and here it appears to be deployed to promote harmony at the sub-textual level as well as to embed a further dimension of symbolism. Pleasure and pain admit the "more and less" and belong to the Unlimited, as was established. A body not moved in any way experiences neither pleasure nor pain, but "we are always experiencing one or the other, as the wise men say, for everything is in eternal flux, upward and downward" (43a). These "wise men" are clearly Heracleitus and his followers. ${ }^{12}$ To Heracleitus, the natural transformations in the cosmos involved contraries, like pleasure and pain, in a state of perpetual flux. ${ }^{13}$ However, in his "conflict of opposites there is a hidden harmony, symbolised by the tension of a bow or the attunement of a lyre". ${ }^{14}$ Heracleitus' underlying source of unity appears to have been a law of process and opposition. Moreover, he had been critical of Pythagoras and Xenophanes for undertaking their researches without this insight.

10. See Constance Chu Meinwald, "Prometheus' Bounds: Peras and Apeiron in Plato's Philebus," in Method in Ancient Philosophy, ed. J. Gentzler (Oxford: Clarendon Press, 1997), 165-180.

11. Plato, Statesman, Philebus, Ion, trans. Harold N. Fowler (London: Heinemann, 1975), 252-3. See David Kolb, "Pythagoras Bound: Limit and Unlimited in Plato's Philebus", Journal of the History of Philosophy 21 (1983): 497-51.

12. Plato, Statesman, Philebus, Ion, trans. Harold N. Fowler (London: Heinemann, 1975), 315.

13. The phrase "everything flows" (ta panta rhei) is attributed to Heracleitus by later sources (e.g. Simplicius' commentary on Aristotle's Physica 1313.11) but is implicit in Plato's Cratylus, see below.

14. Audi Robert, The Cambridge Dictionary of Philosophy, 2nd ed. (Cambridge: Cambridge University Press, 1999), 376. 
Plato's opposition to Heracleitan views, while at the same time being influenced by them, is well attested. It is a leitmotif in a number of his works. In the Symposium, at the dissonant second $7^{\text {th }}$ note (on the Orphic scale) $)^{15}$ and directly prior to note 3.2 on the Pythagorean scale, Eryximachus asserts that Heraclitus' definition is faulty. ${ }^{16}$ At note 3.2 , he corrects the Heracleitan definition which then marks one of the most harmonious notes in the dialogue. ${ }^{17}$ The doctrine of flux helped to shape Plato's own metaphysics inasmuch as, in opposition to it, he posited an indelible Unity in which Heracleitan changes are illusory, consequential manifestations of the Forms in temporal space/time. ${ }^{18}$

In the Philebus, much as with the Symposium, discussion of Heracleitan views falls in close proximity to a dissonant note of the Orphic scale, the $4^{\text {th }}$, only to be harmonised later in the discussion. Plato's allusion to Heracleitus here is a symbolic gesture that appears to self-consciously highlight the musical structure of the Philebus itself. It is harmonious, occurring at a more consonant note in the dialogue, in the sense that it addresses the problematic Heracleitan view while demonstrating its limitations. The dissonant argument of (unlimited) flux is subjected here to the power of the Limited and harmonised by it.

A similar situation arises at the end of dissonant Pythagorean note 7. It is likewise harmonised with recourse to some fundamentally Pythagorean theories. Note 7 (44a6-48d5) addresses notions of pleasure that Socrates rejects. People who believe they experience pleasure when not in pain have made a false judgement. This is because freedom from pain and pleasure each have distinct natures. Base pleasures, particularly associated with tragedy and comedy in the preceding lines, are identified with a "mixed state" and again classified under the Unlimited (46b ff.). ${ }^{19}$ These dissonant views, which Socrates calls "ridiculous", are harmonised at the end of note 7 by means of an ultimate recourse to the Limited, through referencing the axiom of Apollo at Delphi. ${ }^{20}$ Consonant note 8 begins directly after this (48d5) with Socrates applying Pythagorean division to the concept of "Know Thyself". Socrates says that many misunderstand this axiom, believing they have superior virtue, when they do not (49a1-3). The limiter here is Knowledge about physical and metaphysical phenomena. It introduces the discussion that is to follow in the remainder of note 8 .

15. See Walter Burkert, Ancient Mystery Cults (Cambridge MS \& London: Harvard University Press, 1987), 87-8 for Orphic connections with Pythagoreanism and Walter Burkert, Greek Religion (Oxford: Basil Blackwell, 2000), 296-301.

16. This reference to disagreement marks the dissonant second seventh note on the Orphic scale. See $187 \mathrm{a} 3 \mathrm{ff}, 2$ sevenths=187b3-4.

17. Note 3.2=187c8; see Cratylus 440a-c.

18. A. A. Long, "Heracleitus", in The Concise Routledge Encyclopedia of Philosophy (London \& New York: Routledge, 2000), 346-7, 346.

19. Emotions produced by tragedies and comedies, being mixed states of pleasure and pain, are targeted here (48a).

20. See Phaedrus 229e-230a. 
"Know Thyself" was inscribed in the pronaos (forecourt) of the Temple of Apollo according to the periegetic (travelogue) writer Pausanias (10.24.1) whose report supports Plato's reference to it here and elsewhere. ${ }^{21}$ Its origins are obscure. In the Protagoras (343a-343b), Socrates lists the Seven Sages (Thales of Miletus, Pittacus of Mytilene, Bias of Priene, Solon of Athens, Cleobolus of Lindus, Myson of Chinae and Chilon of Sparta) ${ }^{22}$ as sources of the Delphic maxims including "Know Thyself" and "Nothing in Excess". ${ }^{23}$ At Charmides 164d, he tells us that this maxim should be regarded as "a greeting from the god [Apollo]", in lieu of "hello", by way of advice on how to behave when entering his temple. ${ }^{24}$ A comparable quote "Man know thyself; then thou shalt know the Universe and God" is alleged to have been spoken by Pythagoras; however, this is not verifiable. ${ }^{25}$ Even if Pythagoras did not originate the famous quote, his associations with both Delphi and the god Apollo are well known. ${ }^{26}$

Diogenes Laertius, quoting Aristoxenos, tells us that "Pythagoras obtained most of his moral doctrines from the Delphic priestess Themistoclea". ${ }^{27}$ Porphyry makes the more startling (if less plausible) assertion that Pythagoras was Hyperborean Apollo. ${ }^{28}$ Aelian corroborates that he was called this by his followers at Croton. ${ }^{29}$ Diogenes Laertius writes that "the only altar at which he [Pythagoras] worshipped was that of Apollo". ${ }^{30}$ If Pythagoras was regarded, either literally or symbolically as a manifestation of Apollo, then this reference to "Know Thyself" in the Philebus could be taken as his personal "greeting" and as a sign to readers/auditors to pay special attention to what comes next as they are about to metaphorically enter the "temple" of divine Philosophy. And what comes next in the Philebus may certainly be said to be Pythagorean in character and content.

There are a number of passages which deal directly with mathematical/geometrical figures, colour and musical theory which mostly occur in Pythagorean note 8 , one of the more consonant notes. This appears as foregrounding for note 9 , the most consonant, producing a kind of concord

21. See Charmides 164d, Protagoras 343b, Phaedrus 229e, Philebus 48c, Laws 923a and in the potentially dubious I Alcibiades $124 \mathrm{a}, 129 \mathrm{a}, 132 \mathrm{c}$.

22. According to Iamblichus (De vita Pyth. 267), Chilon's daughter, Chilonis, was one of the original Pythagorean community; see S. B. Pomeroy, Spartan Women (Oxford and New York: Oxford University Press, 2002), 10-11.

23. A 10th century, Byzantine scholiast in the Suda attributed the aphorism to Chilon of Sparta alone (schol. in Plat. Philebus 48c, $\Gamma$ 334); see Julian, Oration 7. 211b-c. Burkert, Religion, 148 argues that "Know Thyself" originally meant "know that you are not a god".

24. For Plato's associations with Apollo, see Diogenes Laertius 3.1-2 ff.

25. As quoted in Peter Cajander, Fragments of Reality: Daily Entries of Lived Life (Lincoln, NE: iUniverse, Inc., 2006), 109.

26. Apollo is the principle deity of music and geometry; see Homer, Iliad 1.473 and Plutarch, De mus. 1134b-d, 1146c and Walter Burkert, Greek Religion (Oxford: Basil Blackwell, 2000), 144-9.

27. 8.8, repeated at 8.21 .

28. Porphyry, Vit. Pyth. 28.

29. Varia Historia 2.26. See Walter Burkert, Greek Religion (Oxford: Basil Blackwell, 2000), 144

30. 8.13 . 
between the two. A discussion of colour is set alongside a similar discussion of shapes, which allude to the Platonic figures and solids, as well as to musical notes. In particular, Socrates is concerned with the mixing of colours and the "pure" nature of the colour white. The issue at this stage in the Philebus is the nature of "true pleasures" and how they result from (truly) beautiful things. Perfect shapes are "eternally beautiful", as opposed to transient, and educe a perfect pleasure that is beyond the purely physical. This mathematical approach to beauty is soundly rooted in Pythagorean theory.

In Euclid's Elements, books 1-4 are considered to be Pythagorean mathematics, later codified by Plato's Academy. ${ }^{31}$ Euclid probably received his mathematical training in Athens from Plato's pupils. ${ }^{32}$ Book 6 of the Elements also gives a definition of division, in terms of mean/extreme ratios, that is applicable to Plato's methodology in the later dialogues and especially Philebus. The Elements climax with a presentation of the maths for geometrical atomism found in the five Platonic solids of Timaeus. ${ }^{33}$ As attested by the scholiasts, these "cosmic figures" were likely Pythagorean discoveries. ${ }^{34}$ The "most beautiful" plane figure is said to be the scalene, right-angled triangle "that on which the square on one of the sides about the right-angle is three times the square on the other". ${ }^{35}$

Socrates goes on to explain that the crux of the argument is about purity (of pleasures, sounds, colours etc.). He discusses pure whiteness (to leukon53a1), which is the "truest and most beautiful", compared with mixed variants (53b). This introduces the discussion that falls within harmonious note 9. There are a number of references to, and discourses on, Pythagorean colour theory throughout the Platonic corpus. ${ }^{36}$ The symbolic significance of it, particularly that of white and black, relates prominently to the method of division in Philebus. Aristotle indicates that white embodies the active principle (masculine) while black is the passive (feminine), corresponding with the Pythagorean Limited and Unlimited on the Table of Opposites. ${ }^{37}$

31. The Scholia in Euclid. 4, nos. 2 and 4, say categorically that "this book" and "the whole of the theorems" are Pythagorean discoveries.

32. T. L. Heath, intro., trans. \& com., Euclid: The Thirteen Books of the Elements, 2nd ed. (Cambridge: Cambridge University Press, 1956), vol. 1, 2.

33. Euclid, The Thirteen Books of the Elements, trans. Thomas L. Heath, vol. 1 (Cambridge: Cambridge University Press, 1956), 226, 413-4; vol. 2, 97-8, 294-5, 263.

34. Book 13; see Proclus, Comm. in Euclid. 65.20; and see Euclid, The Thirteen Books of the Elements, trans. Thomas L. Heath, vol. 1 (Cambridge: Cambridge University Press, 1956), 413; See Alcinous, De doctrina Platonis, c. 11; See too Proclus, Comm. in Euclid. 67.6 and 419.15 .

35. Timaeus 54a-b; see Euclid, The Thirteen Books of the Elements, trans. Thomas L. Heath, vol. 2 (Cambridge: Cambridge University Press, 1956), 98.

36. Meno 76c-d, Theatetus 153e-154aff., both referencing Empedokles and Pythgaorean theories of colour; Lysis 217d, Timaeus 67c ff., Euthydemus 303d, the Republic's myth of Er 617a, Laws 947b.

37. Metaphysics 10.7, $1057 \mathrm{~b} 8 \mathrm{ff}$. See too Nicomachean Ethics (2.1106e) for their moral dimension. 
The colour white reportedly held a special significance for the Pythagoreans. ${ }^{38}$ Plotinus refers to the Pythagorean "splendour and white glint of the celestial fire". ${ }^{39}$ The Pythagoreans appear to have considered the colour of the celestial fire to have been a kind of preternatural, shining white, not the visible colour white, its corollary, but the Form of Whiteness itself. ${ }^{40}$ Plotinus also connects colour conceptually with music, sound and beauty. ${ }^{41}$ Sources closer to Pythagoras' own era are few but do provide some corroborating insights. A colour diagram either by Pythagoras or by his immediate followers likely existed because ancient commentators on Empedocles emphasise that he utilised it when mixing red and óchron with the "primary" colours of black and white. ${ }^{42}$ Aristotle took the theories of Empedocles a step further in order to create the "base line", with seven colours, which has applied to all subsequent colour systems up to the time of Isaac Newton. Empedocles' basic assumption was to regard them as actual, physical characteristics of the surface of bodies and not as "subjective phenomena produced by the eye or in the brain as a result of the properties of light". ${ }^{43}$

The notion of colour corresponding with musical notes, developed by the Pythagoreans, was shared by Plato and Aristotle. In de Sensu, Aristotle discuses Empedocles' theory of perception and undertakes an analysis of the mixture of colours, particularly white and black. ${ }^{44} \mathrm{He}$ describes the numerical ratios required for the appropriate mixtures of colours and then relates them to music $(1.3,439 \mathrm{~b}$ ff.). In Philebus, Plato's narrator has made a similar connection between colours, numbers and music. He describes perfect shapes, colours and sounds possessing "absolute beauty" (51d7-10). This is a remarkable statement, if not necessarily surprising. As indicated, note 9 in the Philebus, which would be the "purest" note in the piece, imparts the essential message or "truth" of the dialogue. And truth and beauty are synonymous for Plato.

In discussing musical theory at Philebus 17c11-d8, Socrates tacitly references the Pythagoreans. He is using musical science here, in part, as an analogy to indicate the superiority of the Limited over the Unlimited. He says

38. Diogenes Laertius, Lives of Eminent Philosophers, 8.19 ff.; Walter Burkert, Greek Religion (Oxford: Basil Blackwell, 2000), 280; Porphyry, Vit. Pyth. 17. Neo-Platonists are naturally suspect; yet, they can sometimes provide useful insights - if one can filter out their agendas.

39. Plotinus Ennead, First Tractate, 6.

40. See Plotinus Ennead, First Tractate, 17. In Timaeus, the Platonic solid identified with elemental Fire was the tetrahedron (55d-56a) and there may be some significance here to it being a four-sided figure.

41. Plotinus Ennead Sixth Tractate, 3.

42. Diels fr. 86, Theophrastus, De sensu 1-24 (D. 499n.). John Gage, Color and Culture: Practice and Meaning from Antiquity to Abstraction (Berkeley, CA: University of California Press, 1999), 12 and see John Gage, Colour and Meaning: Art Science and Symbolism (London: Thames and Hudson Ltd., 2006), 85-6 and n. 93 for Empedocles' colour-based atomism.

43. "Pythagoras, Aristotle, Plato," Colorsystem., accessed November 30, 2015. http://bit.ly/1IoLECC.

44. See Metaphysics $10.7,1057 \mathrm{~b} 8 \mathrm{ff}$. 
that one should strive to "become wise in respect to that unity" through the proper understanding of number and the Limited rather than wallowing in "indefinite thought", the Unlimited (17d9-e7). He refers to "forebears" here who can be none other than the Pythagoreans and he has directly referenced their theory of the harmonies and their musical theory in general, which requires closer inspection. ${ }^{45}$

The Pythagoreans were certainly interested in music. They, along with Platonist and Aristotelian musical theorists, measured melody and rhythm mathematically and, thus, developed a fairly precise system of notation for both. ${ }^{46}$ But music also entailed ethical and metaphysical dimensions. Different musical modes were thought to promote certain character types, behaviours and feelings. ${ }^{47}$ They developed a theory of musical influence on human mindstates. ${ }^{48}$ They are reported to have systematically classified, and utilised, types producing different emotional effects on subjects. ${ }^{49}$ Music was perceived to have an association with metaphysical phenomena including metempsychosis and general cosmology - ergo the doctrine of the Harmony of the Spheres. ${ }^{50}$ The absolute beauty of music, as Socrates in the Philebus asserts, resides in its mathematical perfection.

The material covered in note 8 of the Philebus is highly significant to the argument and packed full of Pythagorean references. The ninth note is even more emphatically marked with these. This also appears to be the case in other Platonic dialogues. For example, in Symposium, Diotima's speech on Birth in Beauty, which may be unequivocally considered the central message of that dialogue, spans from notes 8.3-9.0, corresponding with the ascent up her "ladder". There, the dialogue is marked by the Cardinal Virtues at note 8.2 , apprehension of the Forms at 8.3 and the vision of the Form of Beauty at 9.0. ${ }^{51}$ A similar pattern emerges in Philebus. This seems somewhat curious at first since the ninth note (produced by a $4: 3$ ratio) should be marginally less consonant than the eighth note (2:3 ratio). However, the reason for Plato's

45. See 28d where these "forebears" likely refer to the Pythagoreans. See too Richard Janko, "Socrates the Freethinker," in A Companion to Socrates, ed. S. Ahbel-Rappe and R. Kamtekar (London: Wiley-Blackwell, 2006), 48-62, $53 \mathrm{ff}$.

46. Giovanni Comotti, Music in Greek and Roman Culture, trans. R. V. Munson (Baltimore and London: Johns Hopkins University Press, 1989), 110-20.

47. See Walter Burkert, Greek Religion, (Oxford: Basil Blackwell, 2000), 224 on the different ethoi of the musical modes, and 336 for the perceived power of music to summon divinities.

48. See Plato, Republic 398c ff. along with Laws 814-16e.

49. M. L. West, Ancient Greek Music (Oxford: Clarendon Press, 1994), 246; and see Kenneth R. Moore, "Was Pythagoras Ever Really in Sparta?" Rosetta 6 (2009): 1-25, 19-21, accessed 30 November 2015, http://bit.ly/1TxYvn6.

50. See Walter Burkert, Lore and Science in Ancient Pythagoreanism, trans. Edwin L. Minar Jr. (Cambridge, MS: Harvard University Press, 1972), 369-71; see also Pindar Ol. 2.56 ff. (fr. 133), Empedokles, Katharmoi, passim; Hdt. II.123 and Plato Phaedo 81b, Menex. 81a, Phaedrus 248d, Rep. 614 ff., Gorgias 525c.

51. Alcibiades' drunken intrusion and speech come in dissonant note 10; see Kennedy, Musical Structure, 96-97 ff. In the Euthydemus, the ninth note is marked by a reference to Justice, but this is of course associated with the sun in the Republic. 
preference for the ninth may be explained with recourse to a centrally essential feature of Pythagorean symbolism: the tetractys of the decad.

The tetractys (sometimes called the number 4 or the quaternion), credited to Pythagoras' researches, is usually portrayed as an equilateral triangle composed of ten dots. The sum of the first four numbers $(1+2+3+4)$ expresses totality and perfection, signified by the decad, or number 10 . The tetractys symbolises that all things are conceived in unity (One), proceeding through four levels of manifestation, and returning to unity (Ten), once again. ${ }^{52}$ The mathematician and Middle Platonist Theon of Smyrna, amongst others, interpreted aspects of natural and cosmic order through the tetractys model. ${ }^{53}$ Theon concluded that the whole cosmos is based on such quaternaries and therefore "is perfect because everything is part of it, and it is itself a part of nothing else". 54

Recall Philebus 23c-d where the Limited and the Unlimited were two types in this division, and the mixed result of them constituted a third type (eidon). Socrates appears to refer to the generative power of the tetractys at 27e where he says that "we therefore declare that the craftsman who produces all these must be the fourth kind (eidon), the cause". ${ }^{55}$ This classification (the fourth) may simply be a consequence of the process of division and it is difficult to prove as a definitive reference to the tetractys per se; however, since division itself is a consequent of Pythagorean mathematics of Limit and the Unlimited, it would be hazardous to dismiss it. Recall too that the foursided Platonic solid (tetrahedron) was associated in the Timaeus with the element Fire which could be seen as holding particular symbolic significance for the Pythagoreans, connected with "cosmic fire".

"The importance of the quarternion", wrote Theon of Smyrna, "obtained by addition...is great in music because all the consonances are found in it". ${ }^{56}$ All of the basic, consonant musical intervals, indeed, all of the classical tonal divisions of music, are generated by the tetractys (1-4), and Theon lists all combinations from 1:2 to $3: 4$. Thus the ninth note is the most consonant interval generated by the tetractys and this may explain why it is so emphatically marked in Plato. Iamblichus wrote that the tetractys is the

52. See Rachel Fletcher, "The Square," Nexus Network Journal, 7, no. 2 (Autumn 2005): $35-70$.

53. Theon of Smyrna, Mathematics Useful for Understanding Plato, trans. R. Lawlor and D. Lawlor (San Diego, CA: Wizard's Bookshelf, 1979), 87.4-10, 154; Kenneth Sylvan Guthrie, The Pythagorean Sourcebook and Library (Grand Rapids, Michigan: Phanes, 1987), 28-30; Theon of Smyrna, Mathematics Useful for Understanding Plato, trans. R. Lawlor and D. Lawlor (San Diego, CA: Wizard's Bookshelf, 1979), 62-66.

54. ibid. 65-66.

55. See 26e, where he refers to it as the "creative agent" (to de poioun), discussing it in terms that are strikingly similar to the tetractys.

56. Theon of Smyrna, Mathematics Useful for Understanding Plato, trans. R. Lawlor and D. Lawlor (San Diego, CA: Wizard's Bookshelf, 1979), 87.4-10 (Hiller); see J.B. Kennedy, The Musical Structure of Plato's Dialogues (London: Acumen, 2011), 262-3. 
"universal harmony and the music of the spheres". ${ }^{57}$ It represents all harmonies because the first four numbers of it are used in the harmonic ratios of the musical fourth, fifth and the octave. In Plato's myth of Er in Republic, one Siren corresponded to each orbit and was singing a solitary note "and the concord of the eight notes produced a single harmony" (617b) through the actions of the Limited and Unlimited, which are thus mixed together in accord with mathematical harmony (harmonia). ${ }^{58}$

In Philebus, a major theme throughout concerns the distinction between temporal phenomena as opposed to true being itself. Physical pleasure, which Philebus advocates as best, is passing. Knowledge, in its purest form, is associated with being. And the pleasures that arise from the apprehension of the truly Beautiful are regarded as superior to physical ones. At note 9.1 (54d5$10)$, Socrates states that "we ought to be grateful to the person who indicated to us that there is only generation of pleasure and that it has no being whatsoever...he will just laugh at those who claim that pleasure is good". Elsewhere in note 9, he elaborates by discussing the importance of Number and measurement, referring again to the use of instruments like the compass and square, their application to geometry and music. In note 9.2 alone (55e ff.), the monad is thrice mentioned. In 9.3 (57a ff), he brings up geometry and the calculations practiced by philosophers. But who is alluded to in the above passage who will laugh at any who claim temporal pleasure to be a good? Perhaps this is ironic as Pythagoras reportedly "abstained wholly from laughter, and from all such indulgences as jests and idle stories". ${ }^{5}$

From the onset, note 9 is concerned with the distinction between true Being and mere generation. At 58e, at the climax of note 9, Socrates expresses the central message of the dialogue, in no uncertain terms:

Clearly anyone should be able recognise that which I mean: for I take it that those with any share of reason would consider that discipline [dialectics] which is concerned with Being and with that which really is and forever in every way eternally self-same to be by far the truest of all kinds of Knowledge. ${ }^{60}$

This theme is restated throughout the remainder of the dialogue but nowhere as clearly as here. The consonance of notes 8 and 9 is sharply contrasted with dissonant note 10, which follows. Gorgias the sophist is referenced here by Protarchus as claiming that the persuasive arts surpass all others in utility (58a-b). Socrates counters by saying that he is not concerned with finding that art which surpasses others in usefulness; rather, he is

57. Iamblichus De vita Pyth. 82=58C4 and 65. See too Aristotle (De caelo 290b12-15) on the harmony of the spheres. See Republic 530d; See too Euclid, Elements Book 2, def. 2 in Heath, Euclid, $370 \mathrm{ff}$.

58. Fr. 6a. See Carl, A. Huffman, Philolaus of Croton: Pythagorean and Presocratic (Cambridge: Cambridge University Press, 1993), passim.

59. DL 8.19-20.

60. As in the Symposium, the climactic note 9 falls $3 / 4$ the way through the dialogue. See J.B. Kennedy, The Musical Structure of Plato's Dialogues (London: Acumen, 2011), 41. 
concerned with "the greatest regard for clarity, precision and truth" which will no doubt make Gorgias angry $(58 \mathrm{~b}-\mathrm{c}) .{ }^{61}$ There follows a re-statement of Socrates' position on eternal things vs. temporal (61d12-e4).

As well as entailing another jab at Heracleitan flux theory, dissonant note 10 airs a number of views which Socrates considers erroneous. This carries over into note 11 , also dissonant. The remainder of the dialogue continues with Protarchus being mostly, but perhaps not wholly, convinced, and with Philebus and his unnamed allies sticking to their position on pleasure, while Socrates takes up these arguments, reiterating some of his previous points. It ends in a putative state of aporia, as many Platonic dialogues, with Protarchus insisting that there are still issues unresolved.

Yet, we already have our answer to the questions about the Good. The physical conclusion of the dialogue need not express its central meaning, as if it were the final page of a modern mystery novel. The point or message of the Philebus was clearly expressed in note 9, and right at the very end of that note, having built towards it with rising action throughout note 8 and the preceding quarter notes of 9, at the climax of this Platonic "symphony". The remainder is largely anti-climax and epilogue. Even so, within that epilogue there is a neat summary of the conclusions which Socrates has reached. And there he plants a direct reference to Orpheus and music.

His synopsis occurs at 66a-d, accompanied by some concessions from Protarchus who seems to have been won over by this stage. Although, it is he who gets the final lines of the dialogue with a reprise claiming that there are still issues outstanding, while Philebus and his followers remain unconvinced. Socrates' final division results in a hierarchy of betters. First place is held by those things chosen for their "eternal nature" and include measure/tune (metron), ${ }^{62}$ moderation/the golden mean (to metrion), ${ }^{63}$ fitness/due measure (kairion) and others similar to them. The second tier is occupied by symmetry/proportion (to summetron), beauty, perfection, sufficiency and others of that class. Mind and wisdom are third. The fourth entails properties specific to the soul (psychē): knowledge (epistemas), arts (teknas) and true opinions (doxas orthas). ${ }^{64}$ The fifth class is that of pleasures unmixed with pains, "pure pleasures", as he calls them, of the soul itself which accompany knowledge and sometimes perception. Socrates concludes his division with the

61. Plato's opinions on Gorgias and the Sophists are well attested. See Marina McCoy, Plato on the Rhetoric of Philosophers and Sophists (Cambridge: Cambridge University Press, 2007), passim.

62. 66a6-9. LSJ give "tune" and "verse" as alternative translations for metron in Plato and Aristotle.

63. In this form, to metrion can also be "golden mean" (LSJ); see Euclid, The Thirteen Books of the Elements. trans. Thomas L. Heath, (Cambridge: Cambridge University Press, 1956), 137 ff. on Euclid's "golden ratio".

64. 66b10, doxas orthas falls on note 11, quarter note 3. Note 11 is more dissonant, characterised by Protarchus' disagreements with Socrates who strives to win the agon with repeated arguments. 
cryptic phrase: "but on the sixth generation/class/division (hektē d'en genea)", says Orpheus, "end the song's perfect order". ${ }^{65}$

So Philebus, a dialogue concerned with discovering the Good by means of division, concludes with a signpost to some invaluable Pythagorean mathematics and a reference to Orpheus which, to some, would have signified nothing less than the nature of the immortal psyche and ordering of the cosmos. The Pythagorean symbolism embedded in this dialogue is present in greater abundance than can be explained by mere coincidence and does appear to uphold Kennedy's stichometric theory, although more research is needed on this subject. Philebus has proven to be one of the most Pythagorean of the Platonic dialogues and, as such, should stand alongside the Republic, Timaeus and Phaedrus as entailing some of its author's essential teachings that are directly derived from the Pythagoreans, however allegorically concealed or otherwise esoteric.

\section{Bibliography}

Audi, Robert. The Cambridge Dictionary of Philosophy, $2^{\text {nd }}$ ed. Cambridge: Cambridge University Press, 1999.

Burkert, Walter. Greek Religion. Oxford: Basil Blackwell, 2000.

Burkert, Walter. Ancient Mystery Cults. Cambridge, MS \& London: Harvard University Press, 1987.

Burkert, Walter. Lore and Science in Ancient Pythagoreanism. Translated by Edwin L. Minar Jr. Cambridge, MS: Harvard University Press, 1972.

Cajander, Peter. Fragments of Reality: Daily Entries of Lived Life. Lincoln, NE: iUniverse, Inc., 2006).

Comotti, Giovanni. Music in Greek and Roman Culture. Translated by R. V. Munson. Baltimore and London: Johns Hopkins University Press, 1989.

Cooper,M. John and D. S. Hutchinson, (Eds.). Plato: Complete Works. Indianapolis, IN: Hacket, 1997.

Fletcher, Rachel. "The Square." Nexus Network Journal, 7 no. 2 (Autumn 2005): 3570.

"Pythagoras, Aristotle, Plato." Colorsystem. Accessed November 30, 2015. http://bit.ly/1IoLECC.

Plato. Statesman, Philebus, Ion.. Translated by Harold N. Fowler. London: Heinemann, 1975.

Gage, John. Colour and Meaning: Art Science and Symbolism. London: Thames and Hudson Ltd., 2006.

Gage, John. Color and Culture: Practice and Meaning from Antiquity to Abstraction. Berkeley, CA: University of California Press, 1999.

Guthrie, Kenneth Sylvan. The Pythagorean Sourcebook and Library: An Anthology of Ancient Writings Which Relate to Pythagoras and Pythagorean Philosophy. Grand Rapids, Michigan: Phanes, 1987.

Euclid. The Thirteen Books of the Elements. Translated by Thomas L. Heath, Vol. 1, $2^{\text {nd }}$. Cambridge: Cambridge University Press, 1956.

65. 66c9-10, genea here is probably a pun on genos, which Socrates has been using throughout for "type" or "class" in his divisions. 
Huffman, Carl, A. Philolaus of Croton: Pythagorean and Presocratic. Cambridge: Cambridge University Press, 1993.

Janko, Richard. "Socrates the Freethinker". In A Companion to Socrates, edited by S. Ahbel-Rappe and R. Kamtekar, 48-62. London: Wiley-Blackwell, 2006.

Kennedy, J. B. The Musical Structure of Plato's Dialogues. London: Acumen, 2011.

Kennedy, J. B. "Plato's Forms, Pythagorean Mathematics, and Stichometry." Apeiron: a Journal for Ancient Philosophy and Science 43, no 1 (2010): 1-32.

Kingsley, Peter. Ancient Philosophy, Mystery, and Magic: Empedocles and the Pythagorean Tradition. Oxford: Clarendon Press, 1995.

Kolb, David. "Pythagoras Bound: Limit and Unlimited in Plato's Philebus." Journal of the History of Philosophy 21 (1983): 497-51.

Theon of Smyrna. Mathematics Useful for Understanding Plato. Translated by R. Lawlor and D. Lawlor. San Diego, CA: Wizard's Bookshelf, 1979.

Long, A. A. "Heracleitus." The Concise Routledge Encyclopedia of Philosophy. London \& New York: Routledge, 2000, 346-7.

Lynch, Greg. "Limit and Unlimitedness in the Philebus: an argument for the Gadamerian reading." Apeiron 46, no. 1 (2013): 48-62.

McCoy, Marina. Plato on the Rhetoric of Philosophers and Sophists. Cambridge: Cambridge University Press, 2007.

Meinwald, Constance Chu. "Plato's Pythagoreanism." Ancient Philosophy 22 (2002): 87-101.

Meinwald, Constance Chu. "Prometheus' Bounds: Peras and Apeiron in Plato's Philebus." In Method in Ancient Philosophy, edited by J. Gentzler, 165-180. Oxford: Clarendon Press, 1997.

Meinwald, Constance Chu. "One/Many Problems." Phronesis 41 (1996): 95-103.

Moore, Kenneth R. "Was Pythagoras Ever Really in Sparta?" Rosetta 6 (2009): 1-25. Accessed November 30, 2015. http://bit.ly/1TxYvn6.

Pomeroy, Sarah B. Spartan Women. Oxford and New York: Oxford University Press, 2002.

West, M. L. Ancient Greek Music. Oxford: Clarendon Press, 1994. 
